\title{
Situation bounded conceptual organization in children: from action to spatial relations
}

\author{
Anna M. Borghi*, Nicoletta Caramelli \\ Dipartimento di Psicologia, University of Bologna, Viale Berti Pichat 5, \\ 40127 Bologna, Italy
}

Received 1 December 2000; received in revised form 1 October 2002; accepted 1 October 2002

\begin{abstract}
This study performed on children aged 5, 8, and 10 years, deals with conceptual knowledge organization using a word association task. The results show that, at all these ages, the production of thematic relations outnumbers that of taxonomic relations; no thematic-to-taxonomic shift occurs. While children aged 5 years produce more action, temporal, and event relations, older children produce more spatial and property relations. An increased capacity for abstraction allows children aged 8 and 10 years to capture the properties of objects and the spatial layout where objects can be located independently from the specific actions occasionally taking place there. With age, even if events and actions lose their primacy, the perceptual and contextual dimensions of objects play a role in shaping children's knowledge. The results suggest the opportunity to rethink the relevance of the cognitive economy principle in children's conceptual organization.

(C) 2002 Elsevier Science Inc. All rights reserved.
\end{abstract}

Keywords: Conceptual development; Knowledge organization; Categorization; Thematic relations; Situated cognition

\section{Introduction}

Recent studies on conceptual organization suggest that concepts are not well defined and stable entities, but embodied and situation-bounded (Barsalou, 1999; Glenberg, 1997; Smith, 1995). Concepts are not isolated units, but are deeply

\footnotetext{
${ }^{*}$ Corresponding author. Tel.: +39-51-2091822; fax: +39-51-243086.
}

E-mail address: borghi@ psibo.unibo.it (A.M. Borghi). 
related to each other, as the activation of one activates many others (Chaffin, 1992, 1997; Collins \& Loftus, 1975). Conceptual relations are the links that interconnect different concepts and, among the wide variety of conceptual relations, taxonomic and thematic relations play a key role (Barsalou, 1993; Markman, 1989).

Concepts are taxonomically related when they are hierarchically organized from the more to the less inclusive levels or vice versa. A taxonomic relation links a concept to its hierarchically superordinate level concept, as 'dog-animal,' to its lower or subordinate level concept, as 'dog-collie,' and to a concept of the same hierarchical level, as 'dog-cat.' While superordination and subordination relations have a vertical structure, coordination relations have a horizontal structure.

In order to understand properly how the taxonomic architecture works, it is generally assumed that the properties shared by the concepts at the higher and more inclusive level are transferred to the concepts at the lower level but not vice versa. For example, properties true to 'animal,' a superordinate level concept, such as 'living' and 'breathing,' are true also to 'bird,' while properties true to 'bird,' such as 'flying' and 'having a beak,' are shared by all birds but not by all other animals. This hierarchical structure allows us to store information about concepts in an economic way. However, the supposed transitivity of the taxonomic organization has been questioned as it can lead to false inferences and errors. Hampton (1982) has shown that different kinds of hyponimic relations, as, for example, the hyponimic taxonomic relation (A husky is a dog) and the hyponimic functional relation (A dog is a kind of pet) can lead to invalid inferences (A husky in a sled team is a kind of pet).

When concepts are linked by cross-categorical relations, they are said to be thematically related as this kind of relation links different knowledge domains, for example, 'dog' to 'bone' and 'lion' to 'cage.' Thematic relations bind one concept to another by highlighting their co-occurrence in an event or situation, i.e., in a common 'theme.' They include spatial and temporal relations, as well as relations among agents, objects and victims of an action. Many studies have shown that the organization of concepts develops thematically before it develops taxonomically (for a review, see Obsborne \& Calhoun, 1998). It has been shown that 20-month-old children group together objects that are included in the same routine (Fivush, 1987) and that pre-school children use more thematic than taxonomic relations in sorting tasks (Gelman \& Bairgellon, 1983; Markman \& Callanan, 1984). This preference is accounted for by the way children deal with their environment as they build up concepts from everyday actions and events: i.e., from situations or themes (Mandler, 1992, 1998; Nelson, 1986). In this view, the early use of thematic relations helps children's later acquisition of more abstract, hierarchical relations such as those required by the taxonomic conceptual organization (Lucariello \& Nelson, 1985; Lucariello, Kyratzis, \& Nelson, 1992). Thus, according to many authors, once children are able to organize their knowledge in a hierarchical structure, they undergo a thematic-to-taxonomic shift which is responsible for their 
relying on the taxonomic organization of conceptual knowledge in their dealings with the environment.

However, this progression from thematic-to-taxonomic relations has been questioned (Lin \& Murphy, 2001; Obsborne \& Calhoun, 1998). Recent evidence has challenged the primacy of thematic relations in younger children showing that even pre-school children are able to distinguish which kind of relation is required in a specific context. For instance, there is no preference for thematic relations when very young children learn new words. They seem aware that new words refer to single objects rather than to objects plus their thematic associates: e.g., they use the word 'dog' to refer to a dog, not to a dog with a bone in its mouth (Markman \& Hutchinson, 1984; Waxman \& Kosowsky, 1990). Furthermore, in matching-to-sample tasks, their choice between thematic or taxonomic relations can be determined by instructions: The "Can you find another one?" instruction yields taxonomic choices, while the "Which one goes with it?" instruction yields thematic choices (Waxman \& Namy, 1997).

Many authors would surely agree that both thematic and taxonomic organization still play a role in older children's and adults' conceptual organization (Markman, 1989; Sell, 1992). However, to our knowledge, there is no direct evidence supporting this claim. Moreover, it remains an open question as to whether in older children thematic relations are more frequent and more easily accessed than taxonomic ones, i.e., whether they contribute to shaping conceptual knowledge.

\section{Experiment}

This research aims to bring new evidence to these contrasting views by testing the following two related hypotheses.

(1) Traditionally, according to the cognitive economy principle and assuming the shift from thematic-to-taxonomic relations, the relevance of thematic relations in organizing children's conceptual knowledge should decrease with age when taxonomic relations become more convenient in order to store an ever increasing amount of structured information. However, recent evidence has shown that concepts can be conceived of as situated and embodied (Barsalou, 1999; Glenberg, 1997; Smith, 1995; Thelen \& Smith, 1994). If this claim holds, then the cognitive economy principle should not play any special role in storing information and no shift from thematic-to-taxonomic relations should occur. In this case, both thematic and taxonomic relations should cooperate in shaping conceptual knowledge organization.

Accordingly the following hypotheses can be advanced:

(a) Provided that thematic and taxonomic biases, due to the task, are prevented, the production both of thematic and of taxonomic relations should be independent of children's age. 
(b) The production of thematic relations should exceed that of taxonomic relations as they convey several kinds of information, e.g., information about locations, functions, etc., while taxonomic relations convey only one kind of information, i.e., information about hierarchical level inclusion.

(2) If conceptual knowledge is rooted in the events children take part in (Mandler, 1992, 1998; Nelson, 1986), younger children are expected to produce more action and event relations than older children as these relations can be directly experienced in everyday life. Older children, instead, due to their greater capacity for abstraction, should profit from contextual and general information more than younger children.

To verify the aforementioned hypotheses a word association task was selected. This task has been already used with success for studying conceptual relations in children (Nelson, 1986). Sell (1992) has used both an oral word association task and a match-to-sample task with children aged from 2 to 10 years. Lucariello et al. (1992) have used an oral word association task, a production task, and a forced-picture-choice task with children aged 4 and 7 years and with adults. The same authors have stressed that the picture-matching-task yields thematic relations more frequently than verbal tasks, which yield taxonomic relations.

Verbal tasks have at least two possible shortcomings. They are affected by children's linguistic capacities and by schooling bias. On the other hand, the match-to-sample task is also biased. Children have simply to choose between two or more alternatives pre-established by the experimenter who is responsible for the relations holding between the chosen objects. The advantage of verbal tasks is to be less transparent to the child than more structured tasks, like the match-to-sample task. Thus, they better allow the surfacing of flexible and variable aspects of children's concepts. Among verbal tasks, the word extension task is widely used as it depends less on children's verbal competence than the simple word association task. Children have to extend a newly taught word to other objects in a set after being given an example of the object referred to by the new word. In this condition, however, children may be tempted to think that there is a right answer, while in a free association task no correct response is expected. In order to avoid all these shortcomings, a written word association task presented as a game was selected to verify the hypotheses. This task clearly resembles the feature listing task that is widely recognized as a good way to access conceptual knowledge in adults (Chaffin, 1997). However, it is less constraining than this last, as children are free to associate any kind of word or phrase to the target concept. Like the feature listing task, the word association task allows the access to both the stable and the variable and flexible aspects of concepts (Barsalou, personal communication; on the relevance of flexible aspects of concepts, see Smith, 1995). Moreover, as the task reveals children's conceptual organization at a given moment, it may provide evidence missed by other tasks. 


\section{Method}

\subsection{Participants}

One hundred and twenty middle class children, 40 aged 5 years, 40 aged 8 years and 40 aged 10 years, attending four different schools (two elementary schools and two kindergartens) in Bologna and the surrounding area participated in the study.

\subsection{Materials}

In order to maintain children's active participation, only nine concept-nouns were selected: three natural kind concepts, three nominal kind concepts, and three artifact concepts (Keil, 1989). For each ontological kind there was one superordinate, one basic and one subordinate level concept. The basic level was defined by the common shape criterion according to which basic level concepts are the most inclusive ones whose members share a common shape (Lassaline, Wisniewsky, \& Medin, 1992). The superordinate and the subordinate levels were defined respectively as the more general and inclusive and the more specific than the basic level. The selected concepts, all countable nouns, were: animal — bird, sparrow; job physician, dentist; furniture - chair, highchair. Even if the selected concepts are few, they are among the most frequently studied, are familiar to children, and are representative of their class. Hence, it is possible to argue that the findings can be generalized.

\subsection{Procedure}

The children were interviewed, one at a time, in their kindergarten or school, in order to grant them a well-known and familiar environment. The free association task was introduced to the children as if it were a game. They were presented with a booklet. On each page there was a circle in the middle of which there was a concept-noun. Children were asked to write on the circle from 5 to 10 nouns, or sentences, that the written noun made them think of linking the given and the produced nouns with an arrow. The circle and the arrow were supposed to prevent children from producing associates of associates in a chain-like fashion and, thus, to reduce schooling bias. Five-year-old children, who were unable to write, were asked to perform the task orally and the experimenter wrote for them. In order to prevent 5-year-olds from using a narrative style, they were invited to tell their associations to the experimenter slowly, so that she could write them down. When children produced five or more associations for a concept, they won a candy. Notwithstanding this reward, the average number of associations produced for each concept by 5-year-olds was 4.37. The average number of associations produced by children aged 8 and 10 years were 5.94 and 5.81, respectively. The lower number of associations produced by younger children further supports that their productions were mere associations and not a continued narrative. At the end 
of the task, the experimenter asked the children to explain their productions and tape recorded their responses.

\subsection{Codes}

Four different kinds of relation were devised, defined as follows:

1. Taxonomic relation (kind of, is a): superordinate, subordinate and coordinate relations: e.g., 'bird-animal,' 'bird-parrot,' 'sparrow-parrot.' The production of taxonomic relations does not imply that children master class inclusion. There is evidence that pre-school children know the subset/superset relation without being aware of both the asymmetry relation and the branching structure which characterize class inclusion that will be developed later (Greene, 1994).

2. Thematic relations that include: (a) spatial relation (where?): the location of the referent of the given concept-noun, as in 'physician - hospital'; (b) temporal relation (when?): the temporal context, as in 'bird - spring'; (c) action relation (who?, what?): the actions which the referent of the given noun take part in, the agent, the recipient of an action, the same action, and, finally, its outcome, as in 'sparrow - fly'; (d) function relation (what for?): the function of the referent of the given concept-noun, as in 'chair — to sit on'; (e) event relation: the description of a complex situation in which the referent of the given noun is involved, as in 'chair - in his castle, a king makes use of the throne and, then, he puts it into his grave for 10 years.'

3. Attributive relations that include: (a) partonomic relation (part of): the production of a part of an object, as in 'bird - beak,' or of a whole of which the given noun is a part, as in 'bird - flock'; (b) property relation (what is it like?): the perceptual or evaluative properties of the referent of the given noun, as in 'chair - brown'; 'physician — expert'; (c) matter relation (made from): the material which the referent of the given noun is made from, as in 'chair — wood' (Chaffin \& Herrmann, 1988; Chaffin, Herrman, \& Winston, 1988).

4. Evaluative relations that include: (a) ego involvement relation: when the child refers to his/her own direct experience of the referent of the given conceptnoun as in 'I saw it often,' or to his/her own affective reaction to it as in 'I hate it'; (b) juxtaposition relation: stereotyped associations between the given and the produced noun, or idiomatic expressions as in 'bird - airplane.'

The relations which could not be included in the previous categories were named 'other.'

\subsection{Data analysis and results}

The associations were transcribed and coded in Childes (Higginson \& MacWhinney, 1991) by two researchers. In case of disagreement (15\% of the 
Table 1

Frequency and percentage of taxonomic thematic, attributive, evaluative and other relations at each age level in children

\begin{tabular}{lccccccc}
\hline & \multicolumn{2}{l}{ Frequencies } & & & \multicolumn{2}{l}{ Percentages } \\
\cline { 2 - 3 } & 5 years & 8 years & 10 years & & 5 years & 8 years & 10 years \\
\hline Taxonomic & 359 & 420 & 402 & & 23 & 20 & 19 \\
Thematic & 887 & 951 & 792 & & 56 & 44 & 38 \\
Attributive & 183 & 680 & 665 & & 12 & 32 & 32 \\
Evaluative & 118 & 78 & 218 & & 7 & 4 & 10 \\
Other & 24 & 8 & 14 & & 2 & 0 & 1 \\
Total & 1571 & 2137 & 2091 & & 100 & 100 & 100 \\
\hline
\end{tabular}

coded relations) the children's productions were discussed by two other judges.

1. According to the first hypothesis, both taxonomic and thematic relations should be produced independently from children's age as there should not be a radical shift from a thematic to a taxonomic conceptual knowledge organization. Moreover, the production of thematic relations should exceed that of taxonomic relations.

As Table 1 clearly shows, the production of taxonomic relations (e.g., furniture - table), about $20 \%$ of the overall relations produced, does not change with age, while that of thematic relations decreases. Chi-square analyses performed in order to compare the distribution of thematic and taxonomic relations show the difference between 5- and 10-year-olds due to the slight decrease of taxonomic and to the consistent decrease of thematic relations at $10\left(\chi^{2}(N=2,440)=6.70, P<.001\right)$. Despite the decline of thematic relations with age, their production at all the age levels greatly exceeds that of taxonomic relations. With age, the thematic organization of knowledge is not replaced by the taxonomic one. Instead, both these kinds of knowledge organization co-exist in children aged 5 years and older.

If the production of taxonomic and evaluative relations remains almost stable and that of thematic relations decreases, then one may wonder what does change during cognitive development. It is the production of attributive relations that increases consistently in both 8- and 10-year-olds. So, older children's knowledge rests more on the parts and the perceptual details of the referents of concepts than that of younger children (Biederman, 1987; Tversky \& Hemenway, 1984).

A Correspondence Analysis was performed on the four groups of relation (taxonomic, thematic, attributive, and evaluative) crossed with the age levels. In Correspondence Analysis the frequencies of the produced relations give rise to a broad data matrix allowing the identification of their weight and their graphical representation as points in a multidimensional space. On the graph, the geometrical proximity of the points shows the degree of their 
association and the similarity of their distribution (Greenacre \& Blasius, 1994; Hair, Anderson, Tatham, \& Black, 1992). The aim of the Correspondence Analysis is to represent the rows and the columns of a two-way contingency table (profiles) as points in corresponding low-dimensional vector spaces. In order to project the observed points onto a low-dimensional subspace, it is necessary to define the Chi-square metric as the distance in the space of the profiles. In fact, the distances between the points are the weighted distances (Chi-square) between the relative frequencies and not the simple Euclidean distances (Hair et al., 1992). Thus, the logic underlying the Correspondence Analysis is quite similar to that of Factor Analysis. Similarly to Factor Analysis, the first dimension explains a Total Inertia higher than that explained by the further dimensions. The maximum number of dimensions is the minimum between the number of columns minus 1 and the number of rows minus 1 .

In the Correspondence Analysis the first dimension, which explains $76 \%$ of the variance, shows the difference between 5-year-olds, who produce thematic relations, and 10-year-olds, who produce attributive relations. The far less relevant second dimension, which explains $24 \%$ of the variance, shows the difference between 8-and 10-year-olds as the production of these last is characterized by the evaluative relations. This means that 10 -year-olds can abstract from the here and now, i.e., from the concrete dimensions of the concept-noun referents, in order to comment on them. Thus, they show an abstraction capacity that allows them to consider their experience at a meta-level.

A more analytical framework is provided by a second Correspondence Analysis performed on all the produced relations (with the exception of the 'other' relations as they are very few) (see Table 2). The first dimension, that explains $86 \%$ of the total variance, shows the difference between 5 -year-olds, who produce action (e.g., physician - he/she prescribes pills), ego involvement (e.g., dentist — I hate him/her), and event relations (e.g., bird — they do the same life as we do), and 10-year-olds who produce property relations (e.g., highchair - colored). This result supports the hypothesis that children organize their knowledge first on everyday events and routines holistically conceived, i.e., they produce actions and events. Only later do they focus on the particular aspects of the elements that give rise to events and routines, i.e., properties, thus showing a more analytical attitude.

2. According to the second hypothesis on the development of thematic relations, younger children are expected to refer to specific situations and events (action and event relations) rather than to stable contextual information.

Table 2 clearly shows that children aged 8 and 10 years produce almost no event relations. The production of action (e.g., bird - flies), function (e.g., highchair to seat), and temporal relations (e.g., physician — when somebody is ill) in both 8 - and 10-year-olds decreases. On the contrary, the production of spatial relations 
Table 2

Frequency and percentage of each relation at each age level in children

\begin{tabular}{|c|c|c|c|c|c|c|}
\hline & \multicolumn{3}{|c|}{ Frequencies } & \multicolumn{3}{|c|}{ Percentages } \\
\hline & 5 years & 8 years & 10 years & 5 years & 8 years & 10 years \\
\hline Taxonomic & 359 & 420 & 402 & 23 & 20 & 19 \\
\hline Thematic spatial & 240 & 466 & 398 & 15 & 22 & 19 \\
\hline Thematic temporal & 39 & 10 & 23 & 3 & 0 & 1 \\
\hline Thematic action & 426 & 378 & 300 & 27 & 18 & 14 \\
\hline Thematic function & 98 & 96 & 70 & 6 & 4 & 3 \\
\hline Thematic event & 84 & 1 & 1 & 5 & 0 & 0 \\
\hline Attributive partonomic & 78 & 203 & 140 & 5 & 10 & 7 \\
\hline Attributive property & 93 & 403 & 461 & 6 & 19 & 22 \\
\hline Attributive matter & 12 & 74 & 64 & 1 & 3 & 3 \\
\hline Evaluative ego involvement & 96 & 18 & 56 & 6 & 1 & 3 \\
\hline Evaluative juxtaposition & 22 & 60 & 162 & 1 & 3 & 8 \\
\hline Other & 24 & 8 & 14 & 2 & 0 & 1 \\
\hline Total & 1571 & 2137 & 2091 & 100 & 100 & 100 \\
\hline
\end{tabular}

(e.g., bird - nest) increases with age and it is particularly frequent in children aged 8 years.

A Correspondence Analysis was performed on thematic relations alone. The first dimension, which explains $97 \%$ of the total variance, shows that 5-year-olds, who produce event relations, differ from both 8- and 10-year-olds who produce spatial relations. From these results it is possible to conclude that the conceptual organization of thematic knowledge in 5-year-olds rests on events, while in 8-and 10 -year-olds it rests on the contextual framework as expressed by spatial relations. In addition, the percentages of production clearly show that not only event, but also action relations are mainly produced by 5 -year-olds (see Table 2 ). Chi-square analyses confirm the opposite developmental trend of spatial and action relations. From age 5 to both 8 and 10 years the production of action relations decreases, while that of spatial relations increases $\left(\chi^{2}(N=1,510)=59.99, P<.0001\right.$; $\left.\chi^{2}(N=1,364)=60.28, P<.0001\right)$. There is no difference between 8 - and 10 -year-olds' productions.

\section{Discussion}

The results show that there is no shift from a thematic to a taxonomic organization of conceptual knowledge, as it is often assumed in the developmental literature. From age 5 years on, the production of thematic relations decreases, while that of attributive relations increases. Contrary to the expectation derived from the thematic-to-taxonomic shift, the ratio of the taxonomic relations does not change consistently with age. At all the age levels considered in this study, children produced more thematic than taxonomic relations, which last represent abstract 
knowledge. This leads us to argue that the cognitive economy principle is neither the only, nor the principal, organizer of conceptual knowledge. This finding is also supported by recent evidence on the lack of a consistent preference for either thematic or taxonomic relations by pre-school children (Obsborne \& Calhoun, 1998; Waxman \& Namy, 1997) and on conceptual flexibility and variability (Smith \& Samuelson, 1997; Barsalou, 1993) as well.

With development, children's knowledge rests less on event and action relations and more on spatial relations. Children embed actions into spatial frames that provide a principled way to generalize objects and actions. The decrease of action relations and the increase of attributive relations in children's productions means that children's knowledge, which is initially grounded in their own or other people's direct action, becomes more directed to objects' details, and particularly to their perceptual properties. The parallel increase in the production of spatial, property as well as juxtaposition relations, these last implying a judgement, means that children overcome the hic et nunc of their specific experiences. This change may be the result of an increase in capacity for abstraction which leads children both to generalize events according to the spatial contexts in which they take place and to detach objects from the events.

This abstraction process allows them to focus on the properties of objects as well as the spatial layout where they can be located independently from the specific actions occasionally taking place there. While with age event relations disappear and action relations lose their primacy, perceptual and contextual relations increase their relevance in shaping children's knowledge. This supports an embodied and situation-bounded view of conceptual knowledge.

\section{Acknowledgments}

The research reported in this paper was supported by a Ph.D. grant to Anna M. Borghi and by grants from CNR nos. 9504047, 9601807, 9700385, 9800572, CT 11, to Nicoletta Caramelli. We are very grateful to Larry Barsalou for insightful comments on this research and to Giovanna Turrini and Elisabetta Lanzetta for discussions on data coding. We also thank Peter Bryant and two anonymous reviewers for comments on an earlier version of this paper. We are very grateful to Anna Rimini for her check of English language. Lastly, many thanks to the teachers, children, and parents of the following schools in Bologna: Scuole Elementari: di Calderara di Reno; Armandi Avogli; XXI Aprile; Scuole Materne: Cà Selvatica; Caterina De Stefani.

\section{References}

Barsalou, L. W. (1993). Flexibility, structure, and linguistic vagary in concepts: Manifestations of a compositional system of perceptual symbols. In A. F. Collins, S. E. Gathercole, M. A. Conway, \& P. E. Morris (Eds.), Theories of memory (pp. 29-101). Hillsdale, NJ: Erlbaum. 
Barsalou, L. W. (1999). Perceptual symbol systems. Behavioral and Brain Sciences, 22, 577-609.

Biederman, I. (1987). Recognition by components: A theory of human image understanding. Psychological Review, 94, 115-147.

Chaffin, R. (1992). The concept of a semantic relation. In E. Kittay \& A. Lehrer (Eds.), Frames, fields and contrasts: New essays in lexical and semantic organization (pp. 253-288). Hillsdale, NJ: Erlbaum.

Chaffin, R. (1997). Associations to unfamiliar words: Learning the meanings of new words. Memory and Cognition, 25(2), 203-226.

Chaffin, R., \& Herrmann, D. J. (1988). The nature of semantic relations: A comparison of two approaches. In M. Evens (Ed.), Relational models of the lexicon-representing knowledge in semantic networks (pp. 249-294). Cambridge: Cambridge University Press.

Chaffin, R., Herrmann, J., \& Winston, M. (1988). An empirical taxonomy of part-whole relations: Effect of part-whole relation type on relation identification. Language and Cognitive Processes, $3(1), 17-48$.

Collins, A. M., \& Loftus, E. F. (1975). A spreading-activation theory of semantic processing. Psychological Review, 82, 407-428.

Fivush, R. (1987). Scripts and categories: Interrelationships in development. In U. Neisser (Ed.), Concepts and conceptual development: Ecological and intellectual factors in categorization (pp. 234-254). Cambridge: Cambridge University Press.

Gelman, R., \& Bairgellon, R. (1983). A review of some Piagetian concepts. In J. H. Flavell \& E. M. Markman (Eds.), Handbook of child psychology: Cognitive development (pp. 167-230). New York: Wiley.

Glenberg, A. M. (1997). What memory is for. Behavioral and Brain Sciences, 20, 1-55.

Greenacre, M., \& Blasius, J. (1994). Correspondence analyses in the social sciences: Recent developments and applications. London: Academic Press.

Greene, T. R. (1994). What Kindergartners know about class inclusion hierarchies. Journal of Experimental Child Psychology, 57, 72-88.

Hair, J. F., Anderson, R. E., Tatham, R. L., \& Black, W. C. (1992). Multivariate data analysis. New York: Macmillan.

Hampton, J. (1982). A demonstration of intransitivity in natural categories. Cognition, 12, 15-164.

Higginson, R., \& MacWhinney, B. (1991). Childes/BIB. Hillsdale, NJ: Erlbaum.

Keil, F. C. (1989). Concepts, kinds, and cognitive development. Cambridge, MA: MIT Press.

Lassaline, M. E., Wisniewsky, E. J., \& Medin, D. L. (1992). Basic levels in artificial and natural categories. In B. Burns (Ed.), Percepts, concepts and categories (pp. 327-378). Amsterdam: Elsevier.

Lin, E. L., \& Murphy, G. L. (2001). Thematic relations in adults' concepts. Journal of Experimental Psychology: General, 130(1), 3-28.

Lucariello, J., Kyratzis, A., \& Nelson, K. (1992). Taxonomic knowledge: What kind and when? Child Development, 63, 978-998.

Lucariello, J., \& Nelson, K. (1985). Slot-filler categories as memory organizers for young children. Developmental Psychology, 21, 272-282.

Mandler, J. M. (1992). How to build a baby: II. Conceptual primitives. Psychological Review, 99, 587-604.

Mandler, J. M. (1998). The rise and fall of semantic memory. In M. A. Conway, S. E. Gathercole, \& C. Cornoldi (Eds.), Theories of memory (Vol. II, pp. 147-169). Hove, UK: Psychology Press.

Markman, E. M. (1989). Categorization and naming in children: Problems of induction. Cambridge, MA: MIT Press.

Markman, E. M., \& Callanan, M. A. (1984). An analysis of hierarchical classification. In R. J. Sternberg (Ed.), Advances in the psychology of human intelligence (pp. 325-365). Hillsdale, NJ: Erlbaum.

Markman, E. M., \& Hutchinson, J. E. (1984). Children's sensitivity to constraints on word meaning: Taxonomic vs. thematic relations. Cognitive Psychology, 16, 1-27.

Nelson, K. (1986). Event knowledge. Structure and function in development. Hillsdale, NJ: Erlbaum. 
Obsborne, G. J., \& Calhoun, D. O. (1998). Themes, taxons, and trial types in children's matching to sample: Methodological considerations. Journal of Experimental Child Psychology, 68, 35-50.

Sell, M. A. (1992). The development of children's knowledge structure: Events, slots, and taxonomies. Journal of Child Language, 19, 659-676.

Smith, L. B. (1995). Stability and variability: The geometry of children's novel-word interpretations. In F. D. Abraham \& A. R. Gilgen (Eds.), Chaos theory in psychology (pp. 53-72). London: Praeger.

Smith, L. B., \& Samuelson, L. L. (1997). Perceiving and remembering: Category stability, variability and development. In K. Lamberts \& D. Shanks (Eds.), Knowledge, concepts, and categories (pp. 161-195). Hove, UK: Psychology Press.

Thelen, E., \& Smith, L. B. (1994). A dynamic systems approach to the development of cognition and action. Cambridge, MA: MIT Press.

Tversky, B., \& Hemenway, K. (1984). Objects, parts, and categories. Journal of Experimental Psychology: General, 113, 169-193.

Waxman, S. R., \& Kosowsky, T. D. (1990). Nouns mark category relations: Toddlers' and preschoolers' word-learning biases. Child Development, 61, 1461-1473.

Waxman, S. R., \& Namy, L. L. (1997). Challenging the notion of a thematic preference in children. Developmental Psychology, 33, 555-567. 